\title{
The Ceramic Ti02 Low-Pressure Nano-Filtration Membrane Separation Behavior for Single and Mixed lon Salt Solutions
} Banan Hudaib*"1, Rasha Hajarat ${ }^{2}$, Zongwen Liu $^{3}$

\author{
${ }^{1)}$ Al-Balqa Applied University, Faculty of Engineering Technology, Chemical Engineering Department, Amman 11131, Jordan \\ ${ }^{2)}$ Mut'ah University, Department of Chemical Engineering, Al-Karak, Jordan \\ ${ }^{3)}$ University of Sydney, School of Chemical and Biomolecular Engineering, NSW 2006, Australia
}

\begin{abstract}
The objective of this work is to study the separation performance of a tubular $\mathrm{TiO}_{2}$ ceramic nanofiltration membrane operate at low pressures ( 2 bar), and the parameters that would affect the membrane rejection behavior, such as the ions valences, ions type, transmembrane pressure (TMP) values, and membrane zeta-potential. The membrane was used to desalinate water samples containing $\mathrm{NaCl}, \mathrm{NaNO}_{3}$, and $\mathrm{Na}_{2} \mathrm{SO}_{4}$ in single and tertiary salts solution. The rejection of ions solutions took the following trend: $\mathrm{R}$ of sulphate $\left(\mathrm{SO}_{4}{ }^{2-}\right)>\mathrm{R}$ of nitrate $\left(\mathrm{NO}_{3}{ }^{1-}\right)>\mathrm{R}$ of chloride $\left(\mathrm{Cl}{ }^{1-}\right)>R$ of sodium $\left(\mathrm{Na}^{1+}\right)$. The highest $\mathrm{SO}_{4}{ }^{2}$ rejection was about $62 \%$, the highest $\mathrm{NO}_{3}{ }^{1-}$ rejection was about $51 \%$, the highest $\mathrm{Cl}^{1-}$ rejection was about $42 \%$, and highest $\mathrm{Na}^{1+}$ rejection was about $37 \%$.
\end{abstract}

Keywords: Low-pressure nanofiltration; Transmembrane pressure; Separation; Ceramic membrane

\section{Introduction}

Freshwater is very important for all aspects of life. Brackish water and seawater treatment considered a good solution as a source of fresh water. Among all the techniques used for desalination, pressure-driven membrane processes have a prominent position. Membranes processes have dominated the desalination market in recent times (Schäfer et al. 1998). Among their different types, nanofiltration membranes have become the most important advance in membranes technology for their advantages such as low operation pressure, high flux, high retention of multivalent ions and organic molecules and relatively low operation and maintenance cost (Lu et al., 2002).

Nanofiltration (NF) based process is widely used for desalting and purification as alternative separation techniques to the conventional salting-out processes (Morão et al., 2008) as one of the most recently developed membrane separation processes, (NF) has found some industrial applications such as pharmaceutical industry, drinking water treatment, and environmental protection (Bowen and Welfoot, 2002). Nanofiltration (NF) is operating under low pressures (less than 5 bar), potentially opening doors for scale-up implementation of the membrane in low-pressure hard water softening and seawater desalination pretreatment (Labban et al., 2017). Ceramic NF membranes are regarded as the appropriate choice in many applications, due to their temperature stability, resistance towards solvents, narrow pore size distribution (Zhu et al., 2018), several additives were used in the modification of mesoporous and microporous membranes include $\mathrm{Al}_{2} \mathrm{O}_{3}, \mathrm{TiO}_{2}, \mathrm{ZrO}_{2}, \mathrm{SiO}_{2}$. Of these, $\mathrm{TiO}_{2}$ has unique characteristics e.g higher chemical and physical stability, ability to withstand high temperatures; and importantly, long service-life (Bhave, 1991). Much research has been focused on the development of ceramic membranes with a $\mathrm{TiO}_{2} \mathrm{NF}$. The membrane performance can be characterized by the retention of charged and uncharged solutes, as well as the solvent permeability (Schäfer et al. 1998, Mohammad \& Takriff, 2003, Luo \& Wan, 2013).

The separation process in nanofiltration is a combination of sieving and diffusion of molecules through the surface layer of the membrane. Also, surface charges play a more important role in the separation by NF than with other pressure-driven membrane processes (Manttari, 2006). The charge of nanofiltration membrane is a result of dissociating functional groups, adsorption of ions from the solution, adsorption of polyelectrolytes, adsorption of ionic surfactants, and adsorption of charged macromolecules (Luo, 2013, Yazhen \& Lebrun, 1999). When the membrane is charged, then the Donnan effect would contribute to the separation performance. The charged membrane would repel ions with the same charge as the fixed membrane charge; as a result, the ion's concentration in the membrane and the transport rate are low (Luo, 2013, Mohammad \& Takriff, 2003). Nanofiltration can separate charged and uncharged solutes from the solution, (Yazhen \& Lebrun, 1999). The uncharged molecule's separation is a result of the size exclusion or the difference between the diffusion rates.

Received on February 4, 2019; accepted on August 27, 2019 Correspondence concerning this article should be addressed to Banan Ismail Hudaib (Email address: banan.hudaib@bau.edu.jo ORCiD ID of Banan Ismail Hudaib https://orcid.org/0000-0003-2900-6388 
The charged solute's (ions) separation is a result of the interaction between the membrane surface charge and the solute charge. Also, charged molecules separation depends on their size; if the molecule size is bigger than the membrane pore, then it will be retained by the membrane (Luo and Wan, 2013, Yaroshchuk, 2000, Bargeman et al., 2005). Solute permeates through nanofiltration membrane by two mechanisms: convection and diffusion. Convection transfer is affected by the physical parameters such as pressure and conversion rate, while diffusion transfer is affected by the chemical parameters such as concentration and $\mathrm{pH}$. As a result, convection is more effective at high pressure than low pressure and larger ions are better retained by the membrane because convection depends on the physical parameters. Since diffusion depends on the chemical parameters, the chemical selectivity is more important than the physical selectivity in nanofiltration membrane; as a result, the selectivity is much higher at low pressure. Nanofiltration membrane selectivity is high at low pressure because of diffusion, and its retention is high at high pressure because of convection (Yaroshchuk, 2000; Szymczyk et al., 2003). Another factor that affects NF membrane rejections is concentration polarization, which refers to the formation of concentration gradients on the membrane feed and permeates interfaces as different constituents of the feed solution permeates through the membrane at different rates. This change in concentrations at the membrane interfaces leads to a reduction in permeate flux and rejection ratios (Sablani et al., 2001; Labban et al., 2017). The retention in NF of different molecules in solution has been widely investigated (Lebbez et al., 2002, Szoke et al., 2003; Bargeman et al., 2005). Bruggen et al. Studied the separation of mono- and divalent ions from aqueous solution by electrodialysis and nanofiltration in single solute systems (Van der Bruggen et al., 2008). The $\mathrm{pH}$ effect on ion retentions was investigated by (Van Gestel et al., 2002). Bodzek et al. investigate the application of both, the DS-5DK NF membrane and the DS-3-SE RO membrane to softening of well and tap water. Their results revealed that NF, was more permeable than RO, and has sufficient selectivity and is more suited for softening applications (Bodzek et al., 2002). Many researchers studied the developments in low-pressure polymeric NF softening membranes (Fang et al., 2012,2015; Liu et al., 2015).

The aim of this work is to investigate ceramic $\mathrm{TiO}_{2} \mathrm{NF}$ membrane permeation properties, efficiency and separation performance for single and multivalent ions at low pressure. The influence of surface charge (at certain $\mathrm{pH}$ ) and its effect on the separation behavior of the membrane were investigated to obtain the best conditions to enhance the separation performance of nanofiltration membrane.

\section{Materials and Methods 1.1 Materials}

The salts used in the experiments were sodium chloride $(\mathrm{NaCl})$, sodium nitrate $\left(\mathrm{NaNO}_{3}\right)$ and sodium sulfate $\left(\mathrm{Na}_{2} \mathrm{SO}_{4}\right)$ with high purities as follows, $\mathrm{NaNO}_{3} \geq 99 \%, \mathrm{NaCl} \geq 99.5 \%, \mathrm{Na}_{2} \mathrm{SO}_{4} \geq 99.99 \%$. These salts were obtained from Sigma-Aldrich. The solution $\mathrm{pH}$ was controlled using sodium hydroxide $(\mathrm{NaOH} \geq 99.99 \%)$ and hydrochloric acid $(\mathrm{HCl}, 5.0 \mathrm{M})$. $\mathrm{NaOH}$ was also used in the cleaning process of the membrane.

\subsection{Experimental set-up}

A tubular $\mathrm{TiO}_{2}$ ceramic nanofiltration membrane (7.0 mm I.D, 10.0 mm O.D, $190 \mathrm{~mm}$ length and $0.9 \mathrm{~mm}$ mean pore radius, obtained from Inopor gmbh-Germany was used. The concentration of all salts used was $0.1 \mathrm{M}$. To study the separation behavior of the membrane; pure distilled water was used at first, and then distilled water with a single or tertiary salt solution was used. The bench-scale membrane rig is shown in Figure 1. The main components are a variable speed peristaltic pump (type 603S, Watson-Marlow, UK), magnetic stirrer (RW20, IKAMAG, UK), glass container, tubular membrane module, pressure-relief valve, PVC-reinforced flexible piping, neoprene flexible piping for the pump (Watson-Marlow, UK), flowmeter (Gemü Gebr Müller, Germany), pH/ORP controller (Oakton), Accumet pH/Ion/Conductivity meter (Fisher-Scientific, Model 50), balance and stopwatch.

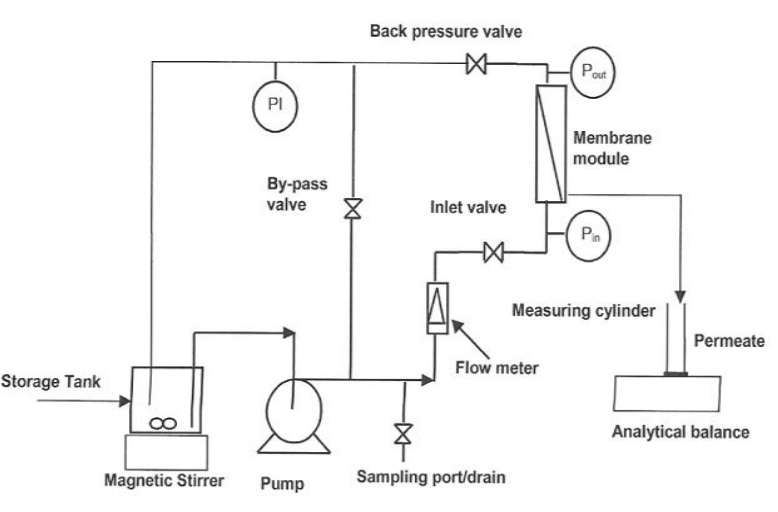

Fig. 1 Schematic diagram of the tubular NF membrane rig.

\subsection{Experimental procedure}

Initially distilled water was used to permeate through the ceramic membrane at constant inlet volumetric flow rate equal to $3.056 \times 10-5$ $\mathrm{m}^{3} / \mathrm{s}(110 \mathrm{~L} / \mathrm{h})$, where the inlet pressure was increased from 0.3 bar to 2.0 bar, which gives transmembrane pressure (TMP) values between 0.2 bar to 1.9 bar, then single and tertiary salt solutions were used to compare the effect of ion type and ion charge on separation. At first sodium chloride $(\mathrm{NaCl})$, sodium nitrate $\left(\mathrm{NaNO}_{3}\right)$ and sodium sulfate $\left(\mathrm{Na}_{2} \mathrm{SO}_{4}\right)$ was prepared as a single solution with $0.1 \mathrm{M}$ concentration. Then a mixed solution of the three salts was prepared at $0.1 \mathrm{M}$ concentration for each salt. The pressure was 
increased by 0.2 intervals every 30 minutes. The permeate was collected for 25 minutes. After each experiment the membrane was cleaned by washing with distilled water several times then it was cleaned with $0.1 \mathrm{M} \mathrm{NaOH}$ solution for 1 hour, and finally, the membrane was washed with distilled water continuously for 6 hours. The anion's concentration was measured by using ion chromatography (Dionex DX600, Dionex AS4A-SC column) and ICP-AES was used to measure the cation concentration.

\subsection{Membrane characterization}

\subsubsection{Membrane rejection}

The rejection $(R)$ of ion (i) using ceramic nanofiltration membrane is given as (Geraldes, 2008)

$$
R=1-\frac{C_{i . p}}{C_{i . f}}
$$

Where $C_{\mathrm{i}, \mathrm{p}}$ is the concentration of ion (i) in the permeate ( $\mathrm{mol} / \mathrm{m}$ ) and $C_{\mathrm{i}, \mathrm{f}}$ is the concentration of ion (i) in the feed (mol/m).

The TMP was calculated as follows (Piry, 2008)

$$
T M P=\left(\frac{P_{\text {inlet }}+P_{\text {outlet }}}{2}\right)-P_{\text {permeate }}
$$

Where the pressure at the permeate side was assumed to be equal to zero, and hence the TMP would be as follows

$$
T M P=\left(\frac{P_{\text {inlet }}+P_{\text {outlet }}}{2}\right)
$$

\subsubsection{Ceramic membrane structural morphology}

Structural morphology of the used membrane was imaged by SEM (FEI Quanta 200, Purge, Czech Republic) and EDXS equipment (Amertek Inc, Paoli, PA, USA). The membrane-active and supporting layers are shown in Figure 2 which shows a thicker skin layer, hence expected higher rejection and lower permeate flux (Chung et al., 2005).

\subsubsection{Zeta potential}

The surface charge of the membrane surface was measured by using the electrophoretic mobility of $\mathrm{TiO}_{2}$ membrane powder derived from the membrane toplayer. This method allows easy evaluation of the charge characteristics of the toplayer (Guizard et al., 1999). The experiment was run at $\mathrm{pH}$ ranging from 3 to 10, at room temperature $(25 \pm 0.50 \mathrm{C})$. Sodium chloride $(\mathrm{NaCl})$ salt $0.1 \mathrm{M}$ concentration was used. The $\mathrm{pH}$ of the solutions was titrated using $0.1 \mathrm{M} \mathrm{HCl}$, and $0.1 \mathrm{M} \mathrm{NaOH}$ solutions. After preparing the solution, the crushed membrane was added to these solutions, and zeta potential was measured.

\section{Results and Discussion}

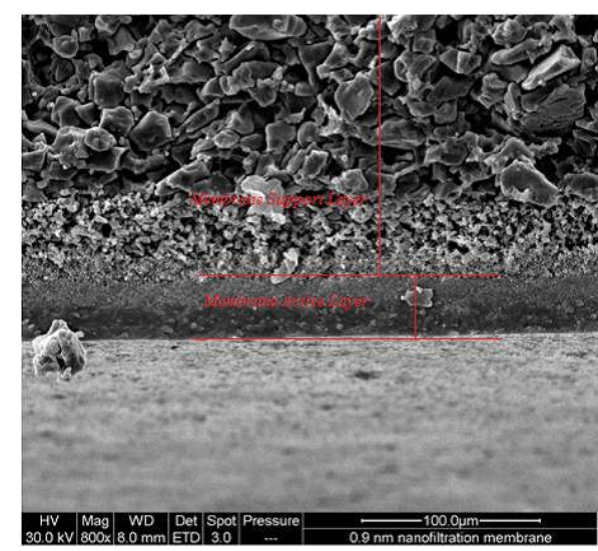

Fig.2 SEM image for ceramic nanofiltration membrane showed the active layer and support layer. Scale bar: $100 \mu \mathrm{m}$.

Studying Zeta potential is considered valuable to understand the interactions between the membrane surface and the solution in contact with the membrane as it has a significant effect on the membrane rejection. As shown in Figure 3, the results of zeta potential measurements stated that the membrane zeta potential decreased as the $\mathrm{pH}$ increased. Hence, the NF membrane has more negative charges and higher hydrophilicity with increasing $\mathrm{pH}$ (Manttari, 2006). The effective membrane, charge corresponds to the inherent charge due to protonation and dissociation of surface hydroxyl groups (Takagi, 2003). The $\mathrm{pH}$ used in all salts experiments was chosen to be 7 at which the zeta potential for the membrane found to be $-20 \mathrm{mV}$. Single and tertiary salt solutions were used to compare the effect of ion type and ion charge on membrane separation. At first sodium chloride $(\mathrm{NaCl})$, sodium nitrate $\left(\mathrm{NaNO}_{3}\right)$ and sodium sulfate $\left(\mathrm{Na}_{2} \mathrm{SO}_{4}\right)$ was prepared as a single solution with $0.1 \mathrm{M}$ concentration. Then a mixed solution of the three salts was prepared at $0.1 \mathrm{M}$ concentration for each salt. For $\left(\mathrm{NaNO}_{3}\right)$ solution, results showed that the rejection of nitrate ions $\mathrm{NO}_{3}{ }^{1-}$ was slightly higher than the rejection of sodium ions $\mathrm{Na}^{1+}$ see Figure 4. The rejections of cations and anions were negative (except at the

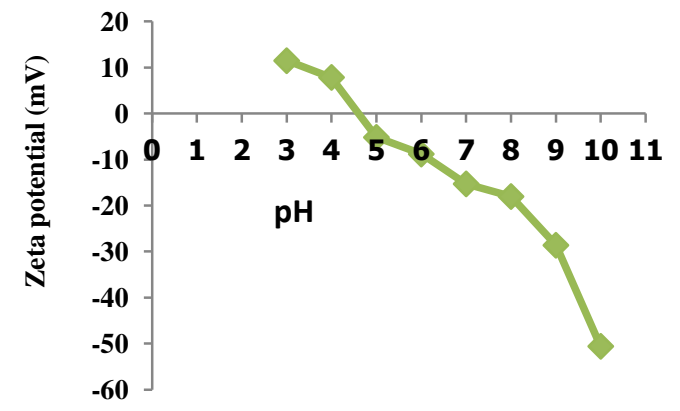

Fig. 3. Zeta potential at $0.1 \mathrm{M}$ concentration 
lowest TMP value,

0.2 bar) same results were reported by Yaroshchuk (Yaroshchuk, 2008). This means that the electrostatic interaction between the membrane and ion charges was not strong enough to overcome the effect of TMP on rejection. Thus, negative rejection does not mean that mass $\left(\mathrm{Na}^{1+}\right.$ solute is this case) is being created, neither the mixture now has more $\mathrm{Na}^{1+}$ ions than it initially started with. Negative rejection only implies that the system has a higher concentration of $\mathrm{Na}^{1+}$ in the permeate, relative to the feed. In other words, negative rejection for a given ion species only occurs when more of that ion is in the smaller permeate volume relative to the much larger feed volume. (Yaroshchuk, 2008; Labban et al., 2017).The higher rejection for both ions was at the lowest TMP at 0.2 bar, the rejection of $\mathrm{NO}_{3}{ }^{1-}$ was about $(63 \%)$ slightly higher than the rejection of $\mathrm{Na}^{1+}$ about $(53 \%)$. Since

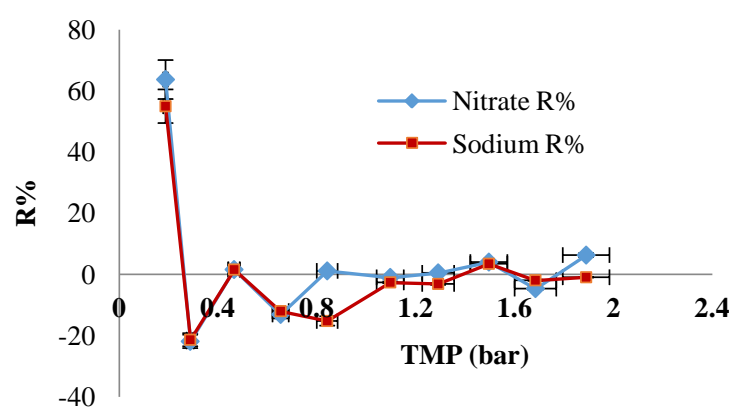

Fig. 4 Sodium nitrate rejection versus TMP at $\mathrm{pH}=7$. The error bars are based on $10 \%$ error in measuring the permeate concentration both ions have the same charge strength, the electrostatic interaction with the membrane charge would be at the same magnitude, and due to neutrality condition at both sides of the membrane, the anion rejection was higher for the ion with bigger size as the size plays an important role in the rejection of $\mathrm{NO}_{3}{ }^{1-}(\mathrm{Pontalier}$ et al., 1997; Nystrom et al., 1995). Additionally, the $\mathrm{NO}_{3}{ }^{1-}$ ion charge plays a role in the rejection as it has the same membrane charge, which caused its repulsion away from the membrane, thus enhancing its rejection (Nystr" om et al.,1995; Garcia et al., 2006). While for Na ${ }^{1+}$, its charge is opposite to membrane charge, leading to increasing its permeation through the membrane, the rejection of cation $\mathrm{Na}^{1+}$ had negative rejection values. Since negative rejection values which imply that the system has a higher concentration of a given ion in the permeate, relative to the feed (Yaroshchuk et al., 2008; Labban et al., 2017). In general, it can be noticed that the rejection of $\mathrm{NO}_{3}{ }^{1-}$ remained almost constant as the TMP increased, while the rejection of $\mathrm{Na}^{1+}$ slightly increased as the TMP increased.

For $\mathrm{Na}_{2} \mathrm{SO}_{4}$ solution permeate, flux increased from $2.8 \times 10^{-8}$ to $5.0 \times 10^{-7} \mathrm{~m}^{3} / \mathrm{m}^{2} / \mathrm{s}$ as the TMP increased. Results found that $\left(\mathrm{SO}_{4}{ }^{2-}\right)$ ions rejection was higher than the rejection of $\left(\mathrm{Na}^{1+}\right)$ ion, see Figure 5. This may be attributed to Donnan exclusion and ion size effect. The electrostatic interaction (Donnan exclusion) between the membrane charge (which is negative) and $\mathrm{SO}_{4}{ }^{2-}$ charge. The high negative valence of $\mathrm{SO}_{4}{ }^{2-}$, causes more repulsion between the negative membrane and $\mathrm{SO}_{4}{ }^{2-}$ charges, which results in more rejection of $\mathrm{SO}_{4}{ }^{2-}$ ion (Garcia et al., 2006; Teixeira et al., 2005, Luo \& Wan, 2013), Similar results were also reported by Szoke et al. (Szoke et al., 2003) for single $\mathrm{Na}_{2} \mathrm{SO}_{4}{ }^{2-}$ and $\mathrm{CaCl}_{2}$ solutions. On the other hand, the cation $\mathrm{Na}^{1+}$ is attracted by the membrane charge and passes freely through the membrane as shown in the results seen in Figure 5. Hence, the rejection of cation $\mathrm{Na}^{1+}$ had some negative rejection values (Yaroshchuk et al., 2008; Labban et al., 2017; Gilron et al., 2001).

For $\mathrm{NaCl}$ solution, results showed that the rejection of chloride $\left(\mathrm{Cl}^{1-}\right)$ ions was higher than the rejection of sodium $(\mathrm{Na} 1+)$ ions see Figure 6. The rejection of $\mathrm{Cl}^{1-}$ ions increased as the TMP increased; This may be due to electrostatic interaction between the membrane charge (which is negative in this case) and the ion charge. Hence, the rejection of $\mathrm{Cl}^{1-}$ is a result of the repulsion between the negative membrane and $\mathrm{Cl}^{1-}$ charges (Pontalier et al.,1997, Luo \& Wan, 2013), this together with $\mathrm{Cl}^{1-}$ ion size made its rejection higher than $\mathrm{Na1}+$ rejection, same results was mentioned by Luo et al. (2013) and Teixeira et al. (2005). The electro-neutrality condition can explain the low rejection of both ions at both sides of the membrane. Where $\mathrm{Cl}^{1-}$ and $\mathrm{Na} 1+$ had to diffuse through the membrane to neutralize the charge on the permeate side. See Fig. 6. The highest rejection of $\mathrm{Cl}^{1-}$ was about $22 \%$ at a TMP value equal to 1.9 bar. On the other hand, the $\mathrm{Na}^{1+}$ rejection increased as TMP increased until it reached 1.5 bar where it decreased afterward. The highest rejection of

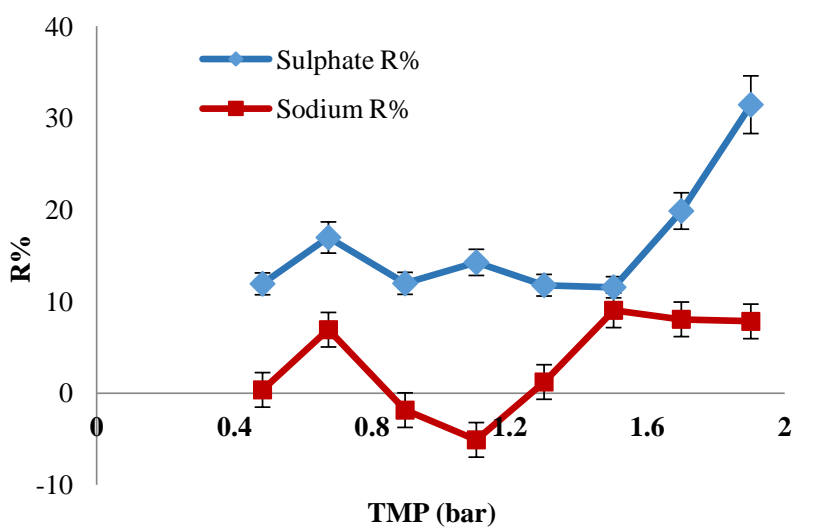

Fig. 5 Sodium sulfate rejection versus TMP at $\mathrm{pH}=7$, The error bars are based on a $10 \%$ error in measuring the permeate concentration.

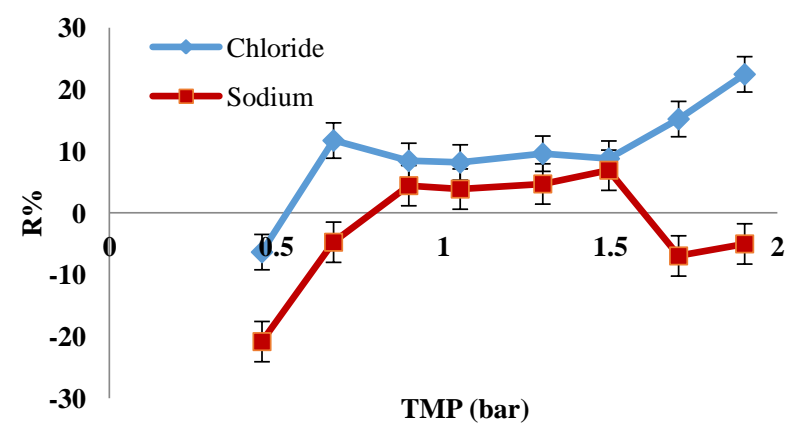

Fig. 6 Sodium chloride rejection versus $\mathrm{TMP}$ at $\mathrm{pH}=7$. The error bars are based on $10 \%$ error in measuring the permeate concentration 
$\mathrm{Na}^{1+}$ was about $8 \%$ at a TMP value equal to 1.5 bar. The mixed salt solution permeates flux increased from $4.7 \times 10^{-}$ ${ }^{9}$ to $5.0 \times 10^{-7} \mathrm{~m}^{3} / \mathrm{m}^{2} / \mathrm{s}$ as the TMP increased. As seen in Figure 7, the rejection of ions took the following trend: $R$ of sulfate $\left(\mathrm{SO}_{4}{ }^{2-}\right)>\mathrm{R}$ of nitrate $\left(\mathrm{NO}_{3}{ }^{1-}\right)>R$ of chloride $\left(\mathrm{Cl}^{1-}\right.$ )$>R$ of sodium $\left(\mathrm{Na}^{1+}\right)$. The rejection of all anions decreased with the initial TMP and remained almost constant as the TMP increased. The highest rejection for all anions was at the lowest TMP. The highest $\mathrm{SO}_{4}{ }^{2-}$ rejection was about $62 \%$, the highest $\mathrm{NO}_{3}{ }^{1-}$ rejection was about $51 \%$, and the highest $\mathrm{Cl}^{1-}$ rejection was about $42 \%$. The rejection of cation $\mathrm{Na}^{1+}$ decreased after the initial TMP and almost stayed constant as the TMP increased. The highest $\mathrm{Na}^{1+}$ rejection was about $37 \%$. In general, cation $\mathrm{Na}^{1+}$ had negative rejection values, which means

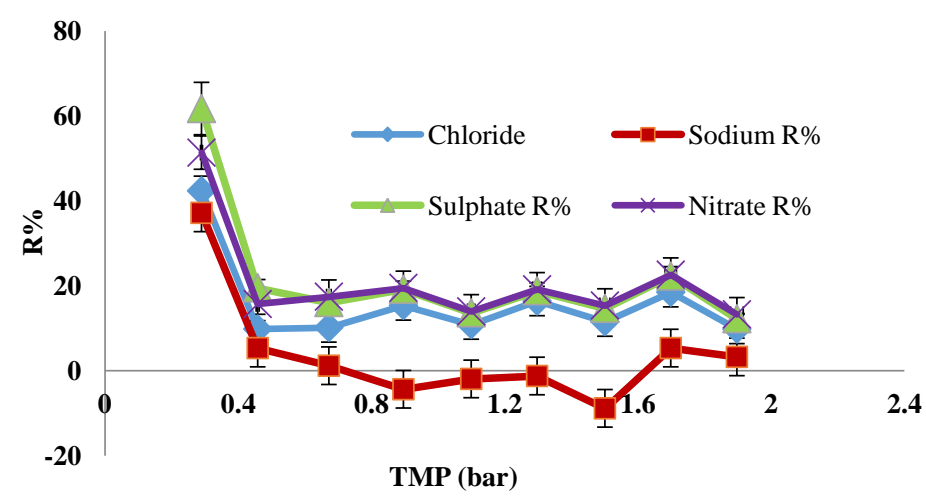

Fig. 7 Mixed salt rejection versus TMP at $\mathrm{pH}=7$. The error bars are based on $10 \%$ error in measuring the permeate concentration that it passed freely through the membrane as explained before (Yaroshchuk et al., 2008; Labban et al., 2017; Gilron et al., 2001). The rejection of ions can be explained by the Donnan exclusion, electro-neutrality condition at both sides of the membrane and ion size. Since the anions had the same charge as the membrane, this would cause repulsion of the anions away from the membrane and back to the solution. Since the cation $\mathrm{Na}^{1+}$ had an opposite charge to the membrane charge, this caused the cation to pass through the membrane and decrease its rejection rate. The ion size influenced rejection where rejection increased as the ion size increased; Furthermore, electro-neutrality played an important role in the rejection of ions (Pontalier et al., 1997; Luo \& Ding, 2011). To maintain the electro-neutrality condition at both sides of the membrane, ions had to pass through the membrane, which explains the low rejection values for both the cation and the forming $\mathrm{HSO}_{4}{ }^{1-}$. As a result, more $\mathrm{Na}^{1+}$ has to pass through the membrane to maintain the electro-neutrality condition, and this explains the low rejection of $\mathrm{Na}^{1+}$ ion. For higher TMP values, the mentioned conditions above would be considered negligible when comparing them to the pressure force. This might explain the decrease in rejection rate as the TMP increased. Moreover, since it is the main driving force, this would explain why the ion rejections remained constant as the TMP increased. When comparing the separation of ions from a single salt solution and mixed salt solution, it was noticed that the rejection of cation $\mathrm{Na}^{1+}$ from single salt solution or mixed salt solution did not differ. This means that $\mathrm{Na}^{1+}$ was not affected by the anion type or concentration of cation or anions. The same was noticed for $\mathrm{SO}_{4}{ }^{2-}$ and $\mathrm{Cl}^{1-}$ anions, where their rejections from the single salt solution and mixed salt solution were almost similar. This means that their rejections were not affected by the existence of other types of anions. On the other hand, this did not imply for $\mathrm{NO}_{3}{ }^{1-}$ anion, where its rejection from mixed salt solution was higher than its rejection from the single salt solution.

\section{Conclusions}

The present study has investigated the separation behavior of ceramic NF membrane under low-pressure for single and tertiary combinations of mixed salts solutions containing sodium chloride $(\mathrm{NaCl})$, sodium nitrate $\left(\mathrm{NaNO}_{3}\right)$, and sodium sulfate $\left(\mathrm{Na}_{2} \mathrm{SO}_{4}\right)$. It was found that the trend of rejection of ions as the following: $\mathrm{R}$ of sulphate $\left(\mathrm{SO}_{4}{ }^{2-}\right)>\mathrm{R}$ of nitrate $\left(\mathrm{NO}_{3}{ }^{1-}\right)>\mathrm{R}$ of chloride $\left(\mathrm{Cl}^{1-}\right)>\mathrm{R}$ of sodium $\left(\mathrm{Na}^{1+}\right)$. The rejection of the common $\mathrm{Na}^{1+}$ cation from single and mixed salt solutions by $0.9 \mathrm{~nm}$ ceramic $\mathrm{TiO}_{2}$ nanofiltration membrane was found to be independent of the anion type where Na1+ cation had the lowest rejection from single salt and mixed salts solutions. The rejections of $\mathrm{SO}_{4}{ }^{2-}$ and $\mathrm{Cl}^{1-}$ anions from single and mixed salts solutions were found to be independent of the anion type. The rejection of the $\mathrm{NO}_{3}{ }^{1-}$ anion from the mixed salt solution, was found to be higher than from a single salt solution. Except at the lowest TMP was the rejection of the $\mathrm{NO}_{3}{ }^{1-}$ anion from the mixed salt solution was found to be lower than from a single salt solution.

\section{Nomenclature}

$\begin{array}{lll}C_{i, p} & =\text { Concentration of ion i in permeate } & {\left[\mathrm{mol} / \mathrm{m}^{3}\right]} \\ \mathrm{C}_{\mathrm{i}, \mathrm{f}} & =\text { Concentration of ion i in feed } & {\left[\mathrm{mol} / \mathrm{m}^{3}\right]} \\ \mathrm{M} & =\text { Molarity } & {[\mathrm{mol} / \mathrm{L}]} \\ \mathrm{NF} & =\text { Nanofiltration membrane } & {[-]} \\ \mathrm{P}_{\text {permeate }} & =\text { Pressure at the permeate side } & {[\mathrm{bar}]} \\ \mathrm{R} & =\text { Rejection of ion } & {[\%]} \\ \mathrm{TMP} & =\text { Transmembrane pressure } & {[\mathrm{bar}]}\end{array}$




\section{References}

Abdul-Wahab M., Sobri T., "Predicting flux and rejection of multicomponent salts mixture in nanofiltration membranes", Desal., 157, 105-111 (2003).

Baldeón T., "Studies of electrically enhanced membrane processes", Thesis, Department of Chemical Engineering, The University of Manchester Institute of Science and Technology (2002).

Bargeman, G., Vollenbroek J., Straatsma J. Schroen C., and Boom R., "Nanofiltration of multi-component feeds, Interactions between neutral and charged components and their effect on retention", J. Membr. Sci., 247, 11-20 (2005).

Bhave, R., "Inorganic Membranes Synthesis, Characteristics and Applications",1st Ed., Van Nostrand Reinhold, New York (1991).

Bodzek, M., Koter S., and Wesołowska K., "Application of membrane techniques in a water softening process", Desal., 145,1-3, 321-327 (2002).

Bowen, V.,. and Welfoot J., "Predictive modeling of nanofiltration: membrane specification and the process of optimization", Desal., 147, 197-203 (2002).

Cavaco M., A., Szymczyk A., Fievet P., and Brites A., "Modelling the separation by nanofiltration of a multi-ionic solution relevant to an industrial process", $J$. of Memb. Sci., 322, 320-330 (2008).

Childress, A., and Menachem E., "Effect of solution chemistry on the surface charge of polymeric reverse osmosis and nanofiltration membranes", J. of Memb. Sci, 119, 253-268 (1996).

Chung, C., Quoc, N., and Hoai, N., "Influence of surface charge and solution $\mathrm{pH}$ on the performance characteristics of a nanofiltration membrane Influence of surface charge and solution $\mathrm{pH}$ on the performance characteristics of a nanofiltration membrane", Sci. and Tech. of Adv. Mater., 6, 246-250 (2005).

Fang, W., Shi L., and Wang R., "Interfacially polymerized composite nanofiltration hollow fiber membranes for low-pressure water softening", J. of Memb. Sci, 430, 129-139 (2013).

Fang, W., Shi L., and Wang R., "Mixed polyamide-based composite nanofiltration hollow fiber membranes with improved low-pressure water softening capability", J. of Memb. Sci, 468, 52-61 (2014).

Garcia, F., Ciceron D., Saboni A., and Alexandrova S., "Nitrate ions elimination from drinking water by nanofiltration: Membrane choice", Sep. and Purif. Tech., 52, 196-200 (2006).

Geraldes, V., de Pinho, M., Fonseca, C., and Duarte, E., "Spiral-Wound Module Nanofiltration of Surface River Water", E-Water Hennef, Germany, 1-13 (2008).

Gilron, J., and Kedem O., "Experimental analysis of negative salt rejection in NF membranes", J. of Memb. Sci., 185, 223-236 (2001).

Guizard, C., Palmeri J., Amblard P., Diaz J., and Lasserre J., "Basic transport phenomena of aqueous electrolytes in sol-gel derived meso and microporous ceramic oxide membranes", Proceedings of the Ninth CIMTEC of World Ceramic Congress on Application to Commercial Ceramic Nanofilter Performance, Florence, Italy, 14-19 June, 202-205 (1999).

Labban O., Chang L., Tzyy H., John H., and Lienhard V., "Fundamentals of Low-Pressure Nanofiltration: Membrane Characterization, Modeling, and Understanding the Multi-Ionic Interactions in Water Softening", J. of Memb. Sci, 521, 18-32 (2017).

Labbez C., Fievet P., Szymczyk A., Vidonne A., Foissy A., and Pagetti J., "Analysis of the salt retention of a titania membrane using the DSPM model: effect of $\mathrm{pH}$, salt concentration and nature", J. of Memb. Sci, 208, 315-329 (2002).

Lu X., X., and Shi L., "Preparation and characterization of NF membrane", J. of Memb. Sci., 201, 1-9 (2002).

Liu C., Shi L., and Wang R., "Crosslinked layer-by-layer polyelectrolyte nanofiltration hollow fiber membrane for low-pressure water softening with the presence of SO4 in feed water", J. of Memb. Sci, 486, 169-176 (2015).

Luo, J. and Ding L., "Influence of $\mathrm{pH}$ on treatment of dairy wastewater by nanofiltration using shear-enhanced filtration system", Desal., 278, 150-156 (2011).

Luo, J. and Wan Y., "Effects of $\mathrm{pH}$ and salt on nano-filtration - a critical review", J. Membr. Sci., 438, 18-28 (2013).

Manttari, M., Pihlajamaki A., and Nystrom M., "Effect of $\mathrm{pH}$ on hydrophilicity and charge and their effect on the filtration efficiency of NF membranes at different pH", J. Membr. Sci., 280, 311-320 (2006).

Nyström, M., Kaipia L., and Luque S., "Fouling and retention of nanofiltration membranes", J. Membr. Sci., 98, 249-262 (1995).

Pontalier, P., Ismail, A. and Ghoul, M "Mechanisms for the selective rejection of solutes in nanofiltration membranes", Sep. and Purif. Tech., 12, 175-181 (1997).

Piry, A., Kühnl W., Grein T., Tolkach A., Ripperger S., and Kulozik U., "Length dependency of flux and protein permeation in crossflow microfiltration of skimmed milk",J. Membr. Sci., 325, 887-894 (2008).

Sablani, S., Goosen M., Al-Belushi R., and Wilf M., "Concentration polarization in ultrafiltration and reverse osmosis: a critical review", Desal., 141, 269-289 (2001).

Schäfer, A., Fane A., and Waite T., "Nanofiltration of natural organic matter: Removal, fouling and the influence of multivalent ions", Desal., 118, 109-122 (1998).

Schäfer, A., Fane A., and Waite T., "Nanofiltration principles and applications", 1st Ed., Elsevier, (2005).

Szoke, S., Patzay G., and Weiser L., "Characteristics of thin-film nanofiltration membranes at various pH-values”, Desal., 151, 123-129 (2003).

Szymczyk, A., Labbez C., Fievet P., Vidonne A., Foissy A., and Pagetti J., "Contribution of convection, diffusion and migration to electrolyte transport through nanofiltration membranes", Adv. in Coll. and Inter. Sci., 103, 77-94 (2003).

Takagi, R., Larbot A., Cot L., and Nakagi M., "Effect of A12O3 support en electric properties of TiO2/ A12O3 membrane formed by sol-gel method", J. of Memb. Sci, 177, 33-40 (2000).

Teixeira, M., Rosa M., and Nyström M., "The role of membrane charge on nanofiltration performance”, J. Membr. Sci., 265, 160-166 (2005).

Van der Bruggen, B., Manttari M., and Nyström M., "Drawbacks of applying nanofiltration and how to avoid them: a review", Sep. Purif. Tech.., 63, 251263(2008).

Van Gestel, T., Vandecasteele C., Buekenhoudt A., Dotremont C., Luyten J., Leysen R., Van der Bruggen B., and Maes G., "Salt retention in nanofiltration with multilayer ceramic TiO2 membranes", J. Membr. Sci., 209, 379-389 (2002).

Wang, X., Zhang C., and Ouyang P., "The possibility of separating saccharides from a NaCl solution by using nanofiltration in diafiltration mode”, J. Membr. Sci., 204, 271-281 (2002).

Yaroshchuk, A., "Asymptotic behaviour in the pressure-driven separations of ions of different mobilities in charged porous membranes", J. of Memb. Sci, 167, 163-185 (2000).

Yaroshchuk, A., "Negative rejection of ions in pressure-driven membrane processes", Adv. in Coll. and Inter. Sci., 139, 150-173 (2008).

Yazhen, X., and Rémi E., "Comparison of nanofiltration properties of two membranes using electrolyte and non-electrolyte solutes", Desal., 122, 95-106 (1999).

Yazhen, X., and Rémi E.,"Investigation of the solute separation by charged nanofiltration membrane: effect of pH, ionic strength and solute type", J. of Memb. Sci, 158, 93-104 (1999).

Zhu, B., Duke, M., Dumée, L., Merenda, A., des Ligneris, E., Kong, L., and Gray, S. "Short review on porous metal membranes-Fabrication, commercial products, and applications", Membr., 8, 1-27 (2018). 